\title{
INTOXICAÇÃO AGUDA POR ALDRIN: RELAÇÃO DOS NIVEIS SÉRICOS COM EFEITOS TÓXICOS NO HOMEM
}

\author{
Wilson Andrade Carvalho* \\ Graciela Brige Matos** \\ Sergio Lima Barros Cruz*** \\ Daisy Schwab Rodrigues**
}

CARVALHO, W.A. et al. Intoxicação aguda por aldrin: relação dos níveis séricos com efeitos tóxicos no homem. Rev. Saúde públ., S. Paulo, 24: $39-46,1990$

RESUMO: Para correlacionar o quadro clínico com níveis séricos de aldrin e dieldrin, foram acompanhados 16 pacientes com intoxicação aguda por formulação de aldrin. Oito deles, de ambos os sexos, com idade de 1 a 37 anos, apresentaram apenas sintomas leves comó náusea e desconforto, e alguns permaneceram assintomáticos. No soro de um deles foi encontrado $16,6 \mathrm{ppb}$ de aldrin e em outro $1,41 \mathrm{ppb}$ de dieldrin. Grupo de cinco pacientes apresentou sintomas de moderada severidade, incluindo náusea, vômitos, sonolência, dispnéia, sudorese, abalos musculares, elevação da tensão arterial e episódios isolados de convulsão, a maioria com restabelecimento do estado de saúde em $24 \mathrm{~h}$. A idade deste grupo variou de 2 a 30 anos e os níveis séricos de aldrin se situaram entre $6,98 \mathrm{ppb}$ e $26,3 \mathrm{ppb}$, enquanto o dieldrin variou entre $82,00 \mathrm{ppb}$ e $314,18 \mathrm{ppb}$. Os três outros pacientes desenvolveram um quadro grave de intoxicaçäo, correspondendo a duas tentativas de suicídio e um de origem ocupacional, com idades de 21 a 35 anos; dois deles foram a óbito, um apresentando dor abdominal, arreflexia, sudorese, dispnéia, hipertermia, leucocitose no início do internamento que evoluiu para leucopenia severa, convulsões generalizadas, coma, insuficiência renal aguda, edema agudo de pulmão e morte no sétimo dia de decorrida a intoxicação; outro apresentou níveis séricos de aldrin de $30,00 \mathrm{ppb}$ e $720 \mathrm{ppb}$ de dieldrin; e outro, com in toxicação mais severa, com êxito letal no terceiro dia de internação, apresentou níveis séricos de 747,3 ppb de aldrin e 1.314,00 ppb de dieldrin. O último paciente, com quadro de alteração do ritmo de sono, desorientação e convulsões, tinha um teor de aldrin sérico de $31,05 \mathrm{ppb}$ e $147,11 \mathrm{ppb}$ de dieldrin. Os resultados encontrados sugerem que não ocorre grande correlação entre os níveis séricos de aldrin ou de seu metabólito dieldrin com os sinais e sintomas clínicos em intoxicaçöes agudas por este inseticida.

DESCRITORES: Aldrin, envenenamento. Dieldrin, sangue. Aldrin, sangue

\section{INTRODUÇÃO}

A grande explosão demográfica verificada nos últimos anos, com expectativa de duplicação da população mundial até o final deste século, tem trazido como conseqüência um grande aumento na demanda de alimentos e, por outro lado, incentivado a agricultura na modernização e adoção de novas técnicas e métodos de controle de pragas que possibilitem incrementar a produtividade agrícola.

Além da aplicação agrícola, há que se destacar, também, a utilização dos praguicidas em campanhas de saúde pública no combate a agentes etiológicos e vetores de diversas doenças transmissíveis em nosso meio.

Por outro lado, estudos de exposição ocupa- cional rural em aplicadores da lavoura cacaueira (Carvalho e col. 4, 1987), bem como em campanhas de saúde pública (Carvalho e col. ${ }^{5}, 1987$ ), têm revelado uma grande desinformação por parte de tais trabalhadores. A grande maioria, constituída de analfabetos, não permite a realização de leitura e compreensão das instruções dos rótulos das embalagens dos praguicidas, bem como um adequado conhecimento dos princípios básicos de manipulação desses produtos e do uso de equipamento de proteção individual.

Associado ao desconhecimento da toxicidade, encontra-se a venda indiscriminada de tais produtos, tornando-os acessíveis a quaisquer pessoas, servindo muitas vezes de instrumento para tentativas criminosas diversas, incluindo tentativas de suicídio. Do mesmo modo, a crescente demanda do uso domissanitário dos praguicidas no combate a

\footnotetext{
* Faculdade de Farmácia da Universidade Federal da Bahia - Campus Universitário de Ondina - 40210 - Salvador, BA, e Escola de Medicina e Saúde Pública da Universidade Católica de Salvador, BA (Brasil).

* Centro Antiveneno da Bahia, Hospital Central Roberto Santos - Rua do Saboeiro, s/ $\mathrm{n}^{\circ}$, Cabula - 40000 - Salvador, BA (Brasil).

*** Faculdade de Farmácia da Universidade Federal da Bahia - Campus Universitário de Ondina - 40210 - Salvador, BA (Brasil).
} 
insetos de incidência doméstica tem contribuído para o aumento das intoxicações acidentais por tais produtos.

O estudo da incidência de intoxicações agudas atendidas pelo Centro Antiveneno da Bahia, de 1983 a 1987, mostra que os praguicidas encontramse em segundo lugar como agente etiológico de tais ocorrências, considerando as intoxicaçðes provocadas por substâncias químicas diversas e plantas tóxicas; entre os praguicidas, os inseticidas organoclorados foram os que mais causaram intoxicaçōes de 1983 a 1985 e a partir daí passaram a liderar os inseticidas organofosforados (Carvalho e col. 6,1988$)$.

$O$ aldrin e o dieldrin têm destacada importância como agentes de intoxicaçðes entre os inseticidas organoclorados, devido à elevada toxicidade aguda e a longo prazo destes compostos.

Após a ingestão, esses inseticidas são rápida e quase completamente absorvidos pelo trato gastrointestinal e transportados pelo sistema porta para o fígado e daí para a corrente sistêmica e diversos tecidos. A pele também constitui uma excelente porta de entrada dos ciclodienos para o organismo humano (Hodge e col. ${ }^{21}$, 1967; Jager ${ }^{25}, 1970$ ). A eficiente absorção dérmica desses inseticidas é de particular interesse nas exposições ocupacionais, uma vez que a contaminação da pele, aliada à precária proteção individual, notadamente nas exposições agrícolas, possibilitará maior absorção, associada ainda à via respiratória.

$\mathrm{O}$ aldrin, após a absorção, sofre rápida metabolização hepática, transformando-se em seu epóxido correspondente, o dieldrin, que é bastante mais tóxico que o composto original e, devido à sua lipossolubilidade, deposita-se no tecido adiposo humano. $O$ epóxido pode sofrer outras reaçzes de metabolização e posterior conjugação, tornando-se assim mais hidrossolúvel e excretado na urina e na bile (Cueto e Hayes 9, 1962; Heath e Vandekar 20, 1964; Hunter e Robinson ${ }^{23}$, 1968; Jager ${ }^{25}$, 1970).

A deposição do dieldrin no tecido adiposo, ou a sua concentração no sangue, alcança um estado dinâmico de equilíbrio com o tempo de exposição e a sua meia-vida biológica tem sido estabelecida em 369 dias (Hunter e Robinson 23, 1968; Hunter e col. $\left.{ }^{24}, 1969\right)$.

Hodge e col. ${ }^{21}$ (1967) constataram que, na maioria das espécies testadas, a dose letal de aldrin ou dieldrin, quando administrada por via oral, situava-se entre 20 e $70 \mathrm{mg} / \mathrm{kg}$.

A ação mais importante do aldrin e dieldrin nas intoxicaçōes agudas é sobre o Sistema Nervoso Central e é caracterizada por cefaléia, mal- estar geral, vertigens, visão borrada, diplopia, anorexia, náusea, vômito, dor epigástrica, sudorese, pa- restesia, tremores, movimentos involuntários lentos e convulsões (Hoogendam e col. 22, 1962; Hodge e col. ${ }^{21}, 1967$; Joy ${ }^{27}$, 1976; Schroeder e col. ${ }^{34}, 1977$ ).

Têm sido também observadas alterações de temperatura, desordens do ritmo do sono e comportamento maníaco (Patel e Rao ${ }^{32}$, 1958; Fry ${ }^{17}$, 1964; Ecobichon e Joy ${ }^{12}, 1982$ ).

As convulsōes induzidas pelos ciclodienos podem ser precedidas de queixas subjetivas, porém, freqüentemente elas ocorrem de forma espontânea ou sem sinais e sintomas prodrômicos (Hogendam e col. ${ }^{22}, 1962$ ).

Alguns sinais prodrômicos têm sido descritos, incluindo cefaléia, distúrbios visuais, sudorese, tontura, insônia, náusea e mal-estar (Cobel e col. ${ }^{8}$, 1967; Gosselin e col. ${ }^{19}, 1976$ ).

Anormalidades de eletroencefalograma (EEG) têm sido constatadas em grande número de indivíduos intoxicados (Hoogendam e col. ${ }^{22}$, 1962; Kazantzis e col. ${ }^{27}$, 1964).

Dosagem de $0,0332 \mathrm{mg} / \mathrm{kg} / \mathrm{dia}$ por longo período de tempo pode causar sinais e sintomas de intoxicação convulsiva ou não-convulsiva em algumas pessoas. Ingestão de $26-44 \mathrm{mg} / \mathrm{kg} / \mathrm{dia}$ causa convulsão e recuperação, ao passo que uma dose de $70 \mathrm{mg} / \mathrm{kg} /$ dia pode ser fatal para o homem (Ecobichon e Joy ${ }^{12}, 1982$ ).

Em contraste com a intoxicação aguda, diversos aplicadores ou manipuladores de aldrin e dieldrin, após repetidas exposições, manifestam uma intoxicação crônica, caracterizada geralmente por cefaléia persistente, distúrbio da visão, tonturas, movimentos musculares involuntários, sudorese, insônia, náusea, mal-estar geral, alteração de reflexos, incoordenação, fibrilação muscular e alteraçōes da personalidade (Ecobichon e Joy ${ }^{12}, 1982$ ). Uma polineuropatia motora semelhante à Síndrome de Guillain-Barré tem sido descrita como complicação rara da exposição Jenkins e Toole $\left.{ }^{26}, 1964\right)$.

O objetivo do presente trabalho foi correlacionar os níveis séricos de aldrin e dieldrin com os achados clínicos em indivíduos com intoxicação aguda com aldrin, incluindo os pacientes assintomáticos e os que tiveram êxito letal.

\section{MATERIAL E MÉTODOS}

\section{Amostragem}

Foram estudados 16 casos de intoxicação aguda por formulação de aldrin, correspondendo a um caso de origem ocupacional, 4 acidentais e 11 intencionais por tentativa de suicídio. Os pacientes intoxicados, de fevereiro a setembro de 1987, foram atendidos pelo Centro de Informações Antive- 
neno da Bahia (CIAVE), no Hospital Roberto Santos. As consultas ou internaços foram realizadas espontaneamente ou os pacientes eram encaminhados por outros médicos ou hospitais com suspeita de intoxicação por substâncias químicas, na maioria das vezes apresentando sintomatologia. $O$ diagnóstico era firmado inicialmente de acordo com o quadro clínico, e na maioria das vezes auxiliado pela apresentação da embalagem do agente químico pelo paciente ou acompanhante. $O$ diagnóstico etiológico era realizado no laboratório de toxicologia da Faculdade de Farmácia da Universidade Federal da Bahia (UFBA), pela determinação cromatográfica dos inseticidas no sangue. Este foi coletado imediatamente após o atendimento hospitalar dos pacientes, correspondendo no máximo a quatro ou cinco horas decorrida a intoxicação, separado o soro e mantendo-o em freezer até o momento da análise dos inseticidas.

$\mathrm{Na}$ tentativa de correlacionar os dados clínicos com os níveis séricos de aldrin e dieldrin, os pacientes foram classificados em grupos, de acordo com a gravidade do quadro clínico em leve, moderado e grave. Foram considerados casos leves (Grupo I) os que apresentaram fraqueza, cefaléia, náusea, vômitos e dor epigástrica. Os moderados (Grupo II), aqueles com os mesmos sinais ou sintomas, incluindo sonolência, dispnéia, sudorese, abalos musculares, tonturas e epiśdios isolados de convulsão que foram controlados e regrediram rapidamente. Foram considerados casos graves (Grupo III) os que apresentaram um ou mais dos sintomas já descritos e ainda hipertermia, insuficiência renal aguda, edema agudo de pulmão, desorientação e desordens psiquiátricas, coma e convulsões subentrantes.

\section{Condições Analíticas}

As determinações de aldrin e dieldrin foram realizadas no soro dos pacientes através do método de Dale e col. ${ }^{11}$ (1966) modificado pela Environmental Protection Agency ${ }^{14}, 1980$. Foi utilizado um cromatógrafo CG-370 com detetor de captura de elétrons, fonte de Tritio, munido de coluna de vidro empacotada com a mistura de 1,5\% OV-17 +1,95\% OV-210 em cromosorb W (HP), 100-120 mesh, com as seguintes condições de otimização: temperatura do injetor $215^{\circ} \mathrm{C}$, temperatura do forno da coluna $200^{\circ} \mathrm{C}$, temperatura do detetor $210^{\circ} \mathrm{C}$, fluxo de nitrogênio de $40 \mathrm{ml} / \mathrm{min}$. Foi também utilizada uma coluna para confirmação empacotada com OV-210 a 5\% e cromosorb W (HP), 100-120 mesh. A atenuação do eletrômetro foi ajustada de modo a se obter uma deflexão na escala do registrador (FSD) em torno de $60 \%$ com a injeção de 100 pg de aldrin.

As determinações laboratoriais complementares foram realizadas por métodos de rotina de análises clínicas (Wintrobe e col. ${ }^{36}$, 1974; Lima e col. $\left.{ }^{29}, 1977\right)$. Não foi possível realizar a determinação do eletroencefalograma (EEG) dos pacientes intoxicados, como parte da avaliação clínica.

\section{RESULTADOS E DISCUSSÃO}

De acordo com o critério adotado de classificar os casos em grupos, segundo a sintomatologia apresentada em leves, moderados e graves, foram encontrados no primeiro grupo oito pacientes, dos quais um com a idade de 1 ano e cinco adultos com idades entre 18 e 37 anos. Quanto à origem, foram observados entre eles dois casos acidentais e seis intencionais por tentativa de suicídio. Os níveis séricos de aldrin, nesses indivíduos, variaram desde não detectado até $16,6 \mathrm{ppb}$, e para o dieldrin, desde não detectado até 1,41 ppb (Tabela 1).

Entre os moderados foram vistos cinco casos, sendo dois acidentais e três intencionais por tentativa de suicídio, com idades de 2 e 30 anos e 19, 28 e 16 anos, respectivamente. Os níveis séricos de aldrin nesse grupo variaram de 6,98 a $26,3 \mathrm{ppb}$ e de dieldrin de 82 a 314,18 ppb (Tabela 2).

Foram encontrados três casos graves, sendo dois intencionais e um ocupacional, com idades de 23,35 e 21 anos, respectivamente (Tabela 3). Os dois primeiros pacientes foram a óbito. No primeiro deles, cujo sangue para análise de inseticidas foi coletado dentro de quatro a cinco horas após o atendimento, a concentração sérica de aldrin foi de $747,3 \mathrm{ppb}$ e de dieldrin de $1.314,00 \mathrm{ppb}$. No segundo б́bito, o sangue foi coletado somente três dias após a intoxicação e os níveis séricos de aldrin foram de $30 \mathrm{ppb}$ e de dieldrin de $720,00 \mathrm{ppb}$. Há de se compreender a diferença entre as concentraç̃es séricas dos inseticidas entre os dois pacientes à luz de dois fatores: a) intensidade da exposição e, a partir daí, a dose absorvida pode ter sido mais intensa no primeiro paciente citado; b) a coleta do sangue para análise dos inseticidas organoclorados no segundo paciente ocorreu após três dias do acidente, possibilitando a excreção de parte do aldrin, como também a metabolização do aldrin e do dieldrin e o armazenamento deste em tecido adiposo. Não puderam ser coletadas amostras de tecido adiposo nesses pacientes para comprovar essa possibilidade. Em outras palavras, a baixa concentração de aldrin encontrada no sangue do segundo paciente não deve corresponder aos niveis imediatamente após o acidente tóxico. No terceiro caso grave, foram encontrados níveis de clorados bastante inferiores aos relatados para os outros casos do grupo, associados à sintomatologia de alteração do comportamento e distúrbios do ritmo do sono, não observados nos demais pacientes.

De acordo com a Tabela 1 é possível observar que em pacientes com níveis séricos de aldrin ou dieldrin inferiores a $20 \mathrm{ppb}$ em geral permanecem assintomáticos. Embora não fosse possível correlacionar os sintomas clínicos com a concentração do inseticida, os resultados desta Tabela sugerem que a maioria desses pacientes ingeriu pequena quanti- 


\section{TABELA 1}

Quadro Clínico e Niveis Séricos de Aldrin e Dieldrin em Intoxicaçōes Agudas Leves por Aldrin (Grupo 1).

\begin{tabular}{|c|c|c|c|c|c|c|}
\hline Paciente & Sexo & Idade & Origem & $\begin{array}{c}\text { Aldrin* } \\
\operatorname{ppb}(\mu g / 1)\end{array}$ & $\begin{array}{l}\text { Dieldrin* } \\
\operatorname{ppb}(\mu g / 1)\end{array}$ & Quadro Clínico \\
\hline C.P.V. & $\mathbf{M}$ & 37 & Intenc. & ND & ND & Assintomático \\
\hline M.F.G.J. & F & 18 & Intenc. & ND & ND & Assintomático \\
\hline E.S.S. & $\mathbf{M}$ & 28 & Intenc. & ND & 1,41 & $\begin{array}{l}\text { Epigastralgia, náuseas, } \\
\text { anorexia, vômitos, cefa- } \\
\text { léia }\end{array}$ \\
\hline M.F.A. & F & 22 & Intenc. & ND & ND & $\begin{array}{l}\text { Sialorréia, agi- } \\
\text { tação,cefaléia }\end{array}$ \\
\hline P.Q.M. & M & 01 & Acident. & ND & ND & Assintomático \\
\hline G.F.G. & F & 28 & Intenc. & 16,6 & ND & Assintomático \\
\hline O.B.S. & M & 27 & Acident. & ND & ND & $\begin{array}{l}\text { Náuseas, vộmitos, sudo- } \\
\text { rese, hipertensăo }\end{array}$ \\
\hline L.A. & F & 24 & Intenc. & ND & ND & $\begin{array}{l}\text { Vômitos, cefaléia e } \\
\text { epigastralgia }\end{array}$ \\
\hline
\end{tabular}

M= Masculino; $\quad F=$ Feminino; $\quad \mathrm{ND}=$ Não detectado.

*A coleta de sangue para determinação do aldrin e dieldrin no soro foi realizada imediatamente após $o$ atendimento hospitalar dos pacientes, correspondendo no máximo a quatro ou cinco horas decorrida a intoxicação.

\section{TABELA 2}

Quadro Clínico e Níveis Séricos de Aldrin e Dieldrin em Intoxicações Agudas Moderadas por Aldrin (Grupo II).

\begin{tabular}{|c|c|c|c|c|c|c|}
\hline Paciente & Sexo & Idade & Origem & $\begin{array}{c}\text { Aldrin } \\
\operatorname{ppb}(\mu \mathrm{g} / 1)\end{array}$ & $\begin{array}{c}\text { Dieldrin } \\
\mathrm{ppb}(\mu \mathrm{g} / 1)\end{array}$ & Quadro Clínico \\
\hline M.S.S. & $\mathrm{F}$ & 19 & Intenc. & 26,30 & 225,00 & $\begin{array}{l}\text { Náuseas, vômitos, dor } \\
\text { epigástrica, sonolência, } \\
\text { convulsões }\end{array}$ \\
\hline M.R.C. & $\mathbf{M}$ & 28 & Intenc. & 18,81 & 314,18 & Vômitos, convulsão \\
\hline G.R.A. & $\mathbf{F}$ & 02 & Acident. & 17,10 & 270,00 & $\begin{array}{l}\text { Vômitos, sonolência, con } \\
\text { vulsão }\end{array}$ \\
\hline A.S.J. & $F$ & 16 & Intenc. & 7,20 & 90,40 & $\begin{array}{l}\text { Náuseas, vômitos, con- } \\
\text { vulsōes }\end{array}$ \\
\hline M.P. & F & 30 & Acident. & 6,98 & 82,00 & $\begin{array}{l}\text { Náuseas, vômitos, dor } \\
\text { epigástrica e abalos mus } \\
\text { culares }\end{array}$ \\
\hline
\end{tabular}

$$
M=\text { Masculino; } \quad F=\text { Feminino. }
$$


TABELA 3

Quadro Clínico e Níveis Séricos de Aldrin e Dieldrin em Intoxicaçס̄es Agudas Graves por Aldrin (Grupo III).

\begin{tabular}{|c|c|c|c|c|c|c|}
\hline Paciente & Sexo & Idade & Origem & $\begin{array}{c}\text { Aldrin } \\
\text { ppb }(\mu g / 1)\end{array}$ & $\begin{array}{c}\text { Dieldrin } \\
\mathrm{ppb}(\mu \mathrm{g} / 1)\end{array}$ & Quadro Clínico \\
\hline A.J.S. & $\mathbf{M}$ & 35 & Intenc. & 747,3 & $1.314,00$ & $\begin{array}{l}\text { Náuseas, vômitos, hiper- } \\
\text { termia, convulsöes, coma, } \\
\text { morte }\end{array}$ \\
\hline A.B.S. & $\mathbf{M}$ & 21 & Ocup. & $30^{4}$ & $720^{*}$ & $\begin{array}{l}\text { Palidez, sudorese, ex- } \\
\text { tremidades frias, dor } \\
\text { abd., dispnéia, apnéia, } \\
\text { ins. renal, coma, con- } \\
\text { vulsðes, morte }\end{array}$ \\
\hline v.s. & F & 23 & Intenc. & 31,05 & 147,11 & $\begin{array}{l}\text { Náuseas, vômitos, sialor- } \\
\text { réia, agitaçăo, tonturas, } \\
\text { desorientaçăo, dispnéla, } \\
\text { sonolência, distúrbio do } \\
\text { ritmo do sono, convulsóes }\end{array}$ \\
\hline
\end{tabular}

$M=$ Masculino; $\quad F=$ Feminino.

* Coleta de sangue para determinação do Aldrin e Dieldrin realizada três dias após a intoxicação.

dade do agente ou provocou vômitos, ou os apresentaram espontaneamente logo após a ingeståo. A concentração sérica de dieldrin detectada em dois dos indivíduos deste grupo encontra-se bastante mais elevada do que aquela relatada para indivíduos da populaçăo geral da Inglaterra, correspondendo a uma variação de 1,4 a 2,5 ppb e de 0,3 a 5,5 ppb para a mesma população dos Estados Unidos (Robinson e Hunter 33, 1966; Jager 25, 1970). Nos demais integrantes do grupo, os níveis sanguíneos foram muito similares aos reportados anteriormente para população geral sem exposição direta a praguicidas (Fernícola e Azevedo ${ }^{16}, 1982$; Wassermann e col. ${ }^{35}$, 1972; Carvalho $\left.{ }^{7}, 1988\right)$. Em "Workshop" realizado em 1972 sobre toxicologia de praguicidas ${ }^{15}$, foi considerado que não se deveria esperar nenhum efeito tóxico quando a concentração sanguínea de dieldrin fosse inferior a 10 ppb.

Concentração sérica de dieldrin em torno de 82 $\mathrm{ppb}$ ou o somatório aldrin + dieldrin de $90 \mathrm{ppb}$ parece sugerir o limiar da intoxicaçăo, uma vez que este valor esteve relacionado a queixas consideradas prodrômicas como náusea, vômito e dor epigástrica, como se pode observar na Tabela 2. Vale ressaltar, como bem assinalou Hoogendam e col. 22 (1962), que a mioclonia indica que está iminente um episódio convulsivo. No presente caso, considerado moderado, não houve convulsão, mas foram constatados abalos musculares.

Por outro lado, quando a concentraçăo sérica atingiu $100 \mathrm{ppb}$ foi possível registrar episódios convulsivos controlados com anticonvulsivantes e que regrediram rapidamente. Neste mesmo grupo foram encontrados pacientes com níveis de dieldrin de 225 a 314,18 ppb e aldrin de 17,10 a 26,30 $\mathrm{ppb}$ que também desenvolveram episódios de convulsão que ocorriam a intervalos maiores e que desapareceram dentro de $24 \mathrm{~h}$, sempre controlados com anticonvulsivantes (Tabela 2 ).

Brown e col. ${ }^{2}$ (1964) observaram em cães que quando os sinais clínicos de intoxicação ocorriam, os níveis de dieldrin no sangue encontravam-se acima de 160 a 170 ppb; sugeriram entåo uma concentração sangüínea de dieldrin em torno de 150 a 200 $\mathrm{ppb}$ como correspondente ao limiar da intoxicação.

Do mesmo modo, resultados descritos por Almeida e col. ${ }^{1}$ (1980) admitiam que níveis de dieldrin de 150 a 200 ppb no sangue periférico de pessoas intoxicadas revelavam o limiar da intoxicação, enquanto valores de 280 a 530 ppb indicavam intoxicação com sintomas clínicos.

Os valores descritos por Brown e col. ${ }^{2}$ (1964) e Almeida e col. ${ }^{1}$ (1980) estão bem mais elevados do que os encontrados no presente estudo, sugerindo 
que pode haver intoxicação grave com concentraçōes de dieldrin mais baixas no sangue, cujo limiar se situou em torno de $100 \mathrm{ppb}$.

Por outro lado, em três dos casos classificados como moderados, onde a concentração de dieldrin foi respectivamente de $90,40 \mathrm{ppb}, 270,00 \mathrm{ppb}$ e $314,18 \mathrm{ppb}$, ocorreram convulsōes sem envolver sintomatologia prévia considerada leve na evolução do quadro tóxico, confirmando o que ficou demonstrado por Hoogendam e col. ${ }^{22}$ (1962) de que convulsões induzidas por ciclodienos podem ocorrer sem sinais prodrômicos ou sintomas premonitórios. Do mesmo modo, estudos em diversas espécies de animais parecem não confirmar uma relaçăo estreita entre sintomas e dose tóxica, embora para determinados efeitos tóxicos, como alteração hepática, já existia um consenso em torno da dose capaz de induzir determinado dano (Hodge e col. ${ }^{21}, 1967$ ).

Mesmo considerando que os animais jovens são mais suscetiveis ao dieldrin, como constatado por Bundren e col. ${ }^{3}$ (1952), parece que a idade não influenciou muito na resposta toxicodinâmica ao agente, uma vez que a paciente de 2 anos, com $270,00 \mathrm{ppb}$ de dieldrin sérico e com $17,10 \mathrm{ppb}$ de aldrin, evoluiu clinicamente de maneira similar aos demais adultos do grupo, que apresentaram níveis de dieldrin variando de 225,00 a $314,18 \mathrm{ppb}$. $O$ mesmo ocorreu em relação ao jovem de 16 anos que apresentou níveis séricos em torno de $100 \mathrm{ppb}$.

Entre os casos graves (Tabela 3), dois foram a 6bito e o outro permaneceu seis dias hospitalizado, apresentando quadro de sialorréia, agitação, tonturas, desorientação, alteração de comportamento, distúrbios na conciliação do sono, dispnéia e convulsбes. Este último paciente, com níveis de dieldrin de $147,11 \mathrm{ppb}$ e somatório aldrin + dieldrin de 178,18 ppb, desenvolveu um quadro clínico semelhante ao descrito por Fry ${ }^{17}$ (1964) em jovens intoxicados por dieldrin, que, além de tontura, vômitos, palpitaç̃es, dor epigástrica e convulsões, apresentaram desordens do ritmo do sono e do comportamento, que persistiram por cerca de sete dias após o envenenamento.

A concentração sérica de aldrin e dieldrin encontrada nos pacientes que tiveram êxito letal situou-se, respectivamente, entre 700 e $1.300 \mathrm{ppb}$, e para o somatório de aldrin e dieldrin foi de $2.061,30 \mathrm{ppb}$ para o primeiro e de $750,00 \mathrm{ppb}$ para o segundo (Tabela 3), concordando com as informações de Almeida e col. ${ }^{1}$ (1980) de que os casos fatais encontravam-se relacionados com $1.000 \mathrm{ppb}$ de dieldrin no soro.

Constatou-se ainda que quanto mais elevada a concentração do inseticida no soro, mais grave é a intoxicação, uma vez que o paciente com maior impregnação dos inseticidas foi a b́bito no terceiro dia após o acidente, ao passo que o segundo, com níveis menores, veio a falecer após o sétimo dia de tratamento. Destaque-se que Garrettson e Curley ${ }^{18}$ (1969) constataram uma proporção entre a concentração de dieldrin na gordura e no soro, de 147:1, após três dias de decorrido o envenenamento, e de 2.200:1 após 179 dias. Com o passar do tempo, essas concentraçбes foram-se reduzindo e após 463 dias eram de apenas $78: 1$, indicando assim uma longa meia-vida para o dieldrin no organismo humano. Essa relação entre concentração sérica e de acumulação no tecido adiposo é muito importante, porque provavelmente será proporcional à concentração do dieldrin no cérebro dos pacientes, como descrito por Dale e col. ${ }^{10}$ (1963) para o DDT. Como o principal alvo de ação do dieldrin é o $\mathrm{SNC}$, como constatado por Joy ${ }^{27}$ (1976) e Schroeder e col. ${ }^{34}$ (1977), é de esperar que quanto maior a impregnação desses tecidos mais grave será o quadro do intoxicado (Hunter e Robinson ${ }^{23}$, 1968).

A maioria dos pacientes apresentou sintomatologia típica de intoxicação entre a primeira e a quarta hora de decorrido o evento tóxico. Os pacientes considerados casos leves tiveram completo restabelecimento dentro das $24 \mathrm{~h}$ e os casos moderados entre 24 e $48 \mathrm{~h}$, enquanto os demais, com quadro grave, tiveram uma evolução clínica menos favorável.

Em relação ao paciente A.B.S., é importante informar que já apresentava crises convulsivas subentrantes com fortes contraturas musculares, rigidez e opistótono nas primeiras quatro horas do internamento e evoluiu para agravamento do quadro nas $24 \mathrm{~h}$ seguintes com hipertermia, inconsciência, sudorese profusa, arreflexia e hipotensão. Após o terceiro dia, o paciente apresentou-se ictérico, urêmico e com dispnéia que evoluiu nos dias subseqüentes para apnéia, insuficiência renal aguda, taquicardia, arritmias, insuficiência respiratória, como edema agudo de pulmão e óbito no sétimo dia da internação. As alterações bioquímicas encontradas após a internação consistiram principalmente de elevaçăo nas taxas de uréia, creatinina, potássio, cálcio e cloro e redução nos valores de proteínas totais e albumina. Em relaçăo ao quadro hematológico, foi observada inicialmente, no primeiro dia de internação, uma leucocitose de 21.700 leucócitos com neutrofilia, desvio para a esquerda e monocitose, 13.200 e 10.700 leucócitos nos $2^{2}$ e $3^{\circ}$ dias, respectivamente, seguido de leucopenia importante de 3.400 leucócitos no sétimo dia, com eosinopenia, linfocitopenia e presença de granulações grosseiras em neutrófilos.

Resultados similares têm sido descritos por outros pesquisadores para intoxicações agudas ou exposições a longo prazo (Emerson e col. ${ }^{13}$, 1964; Wintrobe e col. ${ }^{36}, 1974$; Gosselin e col. ${ }^{19}$, 1976).

Os resultados encontrados no presente estudo sugerem que não ocorre grande correlação entre os níveis séricos de aldrin ou de seu metabólito diel- 
drin com os sinais e sintomas clínicos em intoxicaçסes agudas no homem por este inseticida.

Por outro lado, embora entendendo que o limite de tolerância biológico (LTB) para exposiçz̃es ocupacionais ao aldrin deva ser estabelecido após exaustivos estudos a curto e a longo prazo (OMS, $1975^{31}, 1977^{30}$ ), não sendo este, portando, o objetivo deste trabalho, achamos que o LTB estabelecido na legislação brasileira de saúde ocupacional (NR-
7), de $150 \mathrm{ppb}$ no sangue, encontra-se um pouco elevado, uma vez que neste estudo encontramos pacientes que apresentaram convulsão e outros efeitos tóxicos com níveis séricos em torno de $100 \mathrm{ppb}$. Desse modo, acreditamos que esses limites devam ser revistos, mesmo porque o "Workshop" em praguicidas ${ }^{15}$, realizado na Universidade de Amsterdam, em 1972, preconizava uma concentração sangüínea de dieldrin de $105 \mathrm{ppb}$ não relacionado com os efeitos tóxicos em trabalhadores expostos.

CARVALHO, W. A. et al. (Acute intoxication by aldrin: relationship between clinical signs and serum levels in man. Rev. Saúde públ., S. Paulo, 24: 39 - 46, 1990.

ABSTRATCT: In the attempt to correlate clinical findings with serum levels of aldrin, sixteen patients were followed-up after acute intoxication by this agent. Eight of them, males and females, aged from 1 to 37 years, presented no or light symptoms (some discomfort and nausea). The serum of one of these patients was found to contain $16.6 \mathrm{ppb}$ of aldrin and that of another, $1.41 \mathrm{ppb}$ of dieldrin. A group of five patients, aged from two to 30 years, showed symptoms of moderate severity, reporting nausea, vomiting, drowsiness, dyspnea, sweating mild jerking, rise in blood pressure and convulsions. Of these cases, two were accidental and three were attempted suicides, the majority achieving complete recovery within 24 hours. Serum levels of aldrin were between $6.98 \mathrm{ppb}$ and $26.3 \mathrm{ppb}$ and of dieldrin between 82.00 and 314.18 $\mathrm{ppb}$. We found three severe cases, aged from 21 to 35 years, two attempted suicides and one occupational case. Two of these patients died and one of them presented hypothermia, coma, absence of reflexes and generalized convulsions, and another presented abdominal pain, paleness, sweating, cold extremities, dyspnea, hyperthermia and generalized convulsions. In the first one that died the serum levels were: of aldrin $30.00 \mathrm{ppb}$ and of dieldrin $720 \mathrm{ppb}$. In the other levels of $747.3 \mathrm{ppb}$ of aldrin and $1,314.00 \mathrm{ppb}$ of dieldrin were found. The third had less serious symptoms and presented serum levels of aldrin of 31.05 $\mathrm{ppb}$ and of dieldrin $147.11 \mathrm{ppb}$. These data seem to indicate that the serum levels of aldrin or of its metabolite dieldrin do not show great correlation between clinical signs and acute toxicity, because patients were found that presented serious symptoms, such as convulsions, without presenting other prior clinical signs and in whom the blood levels of aldrin and dieldrin were found to be as low as $7.2 \mathrm{ppb}$ and $90.40 \mathrm{ppb}$, respectively. The lethal blood levels were $700 \mathrm{ppb}$ of aldrin and raged from $720 \mathrm{ppb}$ to $1,314.00 \mathrm{ppb}$ of dieldrin.

KEYWORDS: Aldrin, poisoning. Dieldrin, blood. Aldrin, blood.

\section{REFERÊNCIAS BIBLIOGRÁFICAS}

1. ALMEIDA, W. F.; MELLO, D.; PUGA, F.R.; GAETA, R. Intoxicaçoes profissionais por pesticidas. In: Mendes, $\mathbf{R}$. Medicina do trabalho e doenças profissionais. São Paulo, Sarvier, 1980. p. 515-68.

2. BROWN, V.K.H.; HUNTER, C.G.; RICHARDSON, A. A blood test diagnostic of absorption of aldrin and dieldrin. Brit. J. industr. med., 21: 283-6, 1964.

3. BUNDREN, J.; HOWELL, D.E.; HELLER, V.G. Absorption and toxicity of dieldrin. Proc. Soc. exp. Biol. Med., 79: 236-8, 1952.

4. CARVALHO, W.A.; BERBERT, P.R.; ROCHA, N.V. Avaliação da exposição ocupacional de aplicadores ao hexaclorociclohexano $(\mathrm{HCH})$ na lavoura cacaueira do Estado da Bahia, Brasil. Rev. bras. Saúde ocup., 66: 50-64,1987.

5. CARVALHO, W.A.; BERBERT, P.R.; ROCHA, N.V.P. Serum levels of organochlorine inseticides in health workers exposed to DDT in public health campaigns at the State of Bahia, Brasil. [Apresentado no 2nd Intemational Environmental Chemistry Congress in Brasil, Salvador, Bahia, 1987].
6. CARVALHO, W.A.; RODRIGUES, D.S.; SANTOS, R.J.R.; RAMOS, C.A.; COSTA, M.F.F. Incidência de intoxicaçōes por praguicidas no Estado da Bahia-Brasil, 1983 . 1987. Rev. Soc. bras. Toxicol., 1(1/2): 67-70, 1988.

7. CARVALHO, W.A. Exposição ambiental a inseticidas organoclorados na populaçâo do sul da Bahia-Brasil. Rev. Soc. bras. Toxicol., 1(1/2): 64-6, 1988.

8. COBEL, Y.; HILDEBRANDT, P.; DAVIS, J.; RAASCH, E.; CURLEY, A. Acute endrin poisoning. J. Amer. med. Ass., 202: 489-93,1967.

9. CUETO Jr., C. \& HAYES, W.J. The detection of dieldrin metabolites in human urine. J. Agr. Food Chem., 10: $366-9,1962$.

10. DALE, W. E.; GAINES, T.B.; HAYES Jr., W.J. Poisoning by DDT: relation between clinical signs and concentration in rat brain. Science, 142: 1474-6, 1963.

11. DALE, W.E.; CURLEY, A.; CUETO, C. Hexane extractable chlorinated insecticides in human blood. Life Sci., 5: 47-54,1966. 
12. ECOBICHON, D.J. \& JOY, R.M. Pesticides and neurological diseases. Florida, CRC Press, 1982.

13. EMERSON Jr., T.E.; BRAKE, C.M.; HINSHAW, L.B. Cardiovascular effects of the insecticide endrin. Canad. J. Physiol. Pharmacol., 42: 44-51, 1964.

14. ENVIRONMENTAL PROTECTION AGENCY (EPA). Manual of analytical methods for the analys is of pesticides in humans and environmental samples. Research Triangle Park, N.C., 1980.

15. EPIDEMIOLOGICAL toxicology of pesticide exposure; Report of an International Workshop, Arch. environ. Hlth, 25: $399-405,1972$

16. FERNICOLA, N.A.G. \& AZEVEDO, F.A. Serum levels of organochlorine insecticides in humans in S. Paulo, Brazil. Vet. Hum. Toxicol., 24(2): 91-3, 1982.

17. FRY, D.R. Human dieldrin poisoning. Lancet, 1: 764, 1964.

18. GARRETTSON, L.K. \& CURLEY, A. Dieldrin: studies in a poisoned child. Arch. environ. Hlth, 19: 814-22, 1969.

19. GOSSELIN, R.E.; HODGE, H.C.; SMITH, R.P.; GLEASON, M.N. Clinical toxicology of commercial products. 4th ed. Baltimore, Williams \& Wilkins, 1976. p. 121-4.

20. HEATH, D.F. \& VANDEKAR, M. Toxicity and metabolism of dieldrin in rats. Brit. J. industr. Med., 21: 269-79, 1964.

21. HODGE, H.C.; BOYCE, A.M.; DEICHMANN, W.B.; KRAYBILL, H.F. Toxicology and no effect levels of aldrin and dieldrin. Toxicol. appl. Pharmacol., 10: 613-75, 1967.

22. HOOGENDAM, L.; VERSTEEG, J.P.J.; DE VLIEGER, $M$. Electroencephalograms in insecticide toxicity. Arch. environ. Hlih, 4: 86-94, 1962.

23. HUNTER, C.G. \& ROBINSON, J. Aldrin, dieldrin and man. Food Cosmet. Toxicol., 6: 253-60, 1968.

24. HUNTER. C.G.; ROBINSON, J.; ROBERTS, M. Pharmacodynamics of dieldrin (HEOD). Arch. environ. Hlth, 18: 12-21, 1969.

25. JAGER, K.W. Aldrin, dieldrin, endrin and telodrin. New York, Elsevier Publ., 1970.

26. JENKINS, R.B. \& TOOLE, J.F. Polyneuropathy following exposure to insecticides. Arch. intern. Med., 113: 691-5, 1964.

27. JOY, R.M. The alteration by dieldrin of cortical excitability conditioned by sensory stimul. Toxicol. appl. Pharmacol., 38: 357-68, 1976.

28. KAZANTZIS, G.; MCLAUDHLNN, A.I.G.; PRIOR, P.F. Poisoning in industrial workers by the insecticide aldrin. Brit. J. industr. Med., 21: 46-51, 1964.

29. LIMA, O.A.; SOASER, J.B.; GRECO, J.B.; CALIZZI, J.; CANÇADO, J.R. Métodos de laboratório aplicados d clínica. $5^{2}$ ed. Rio de Janeiro, Ed. Guanabara Koogan, 1977.

30. ORGANIZACION MUNDIAL DE LA SALUD. Comite de Expertos en Métodos Utilizados para Estabelecer Níveis Admisibles de Exposición Profesional a los Agentes Nocivos, Ginebra, 1976. Informe. Ginebra, 1977. (Série de Informes Técnicos, 601).

31. ORGANIZACION MUNDIAL DE LA SALUD. Grupo de Estudio sobre Detección Precoz del Deterioro de la Salud Debido a la Exposición Profesional, Ginebra, 1974. Informe. Ginebra, 1975. (Série de Informes Técnicos, 571).

32. PATEL, T.B. \& RAO, V.N. Dieldrin poisoning in man: a report of 20 cases observed in Bombay State. Brit. med. J., 1: 919-21, 1958.

33. ROBINSON, J. \& HUNTER, C.G. Organochlorine insecticides: concentrations in human blood and adipose tissue. Arch. environ. Hlth, 13: 558-63, 1966.

34. SCHROEDER, M.E.; SHANKLAND, D.L.; HOLLNGWORTH, R.M. The effects of dieldrin and isomeric endrin diols on synaptic transmission in the American Cockroach and their relevance to the dieldrin poisoning syndrome. Pest. Biochem. Physiol., 7: 403-13, 1977.

35. WASSERMANN, M.; NOGUEIRA, D.P.; TOMATIS, L.; ATHIE, E.; WASSERMANN, D.; DJAVAHERIAN, M.; GUTTEL, C. Storage of organochlorine insecticides in people of S. Paulo, Brazil. Industr. Med. Surg., 41(3): 22-5, 1972 .

36. WINTROBE, M.M.; LEE, R.G.; BOGGS, D.R.; BITHELL, T.C.; ATHENS, J.W.; FOERSTER, J. Clinical hematology. 7th ed. Philadelphia, Lea \& Febiger, 1974.

Recebido para publicação em 14/4/1989 Reapresentado em 24/1011989 Aprovado para publicaçäo em 27/12/1989 